Supporting Information for:

\title{
A boron dipyrromethene (BODIPY) based probe for selective passive sampling of atmospheric nitrous acid (HONO) indoors
}

Danial Nodeh-Farahani, ${ }^{a}$ Jordan N. Bentley ${ }^{a}$,Leigh R. Crilley ${ }^{a}$, Christopher B. Caputo ${ }^{\text {a }}$, and Trevor C. VandenBoer*a

Department of Chemistry, York University, Toronto, Ontario M3J 1P3, Canada

*Corresponding author: Trevor VandenBoer (tvandenb@yorku.ca)

\section{Section S1: Synthesis}

\section{General Considerations and Procedures}

All manipulations were performed using Schlenk line under $\mathrm{N}_{2}$ atmosphere and all glassware was oven-dried at $110^{\circ} \mathrm{C}$ before use. Solvents were prepared from an MBraun MB-SPS 800 solvent drying system under $\mathrm{N}_{2}$ atmosphere. Commercially available reagents were purchased from either Sigma-Aldrich, TCl Chemicals, or Oakwood Chemicals and employed without further purification; unless otherwise stated. Chloroform- $d$ and benzene- $d_{6}$ were transferred to Strauss flasks and dried over activated molecular sieves, then degassed using freeze-pump-thaw technique. Experiments monitored by NMR spectrum were conducted in NMR spectrum tubes $\left(8^{\prime \prime} \times 5 \mathrm{~mm}\right)$ sealed with standard plastic caps and wrapped with Parafilm or J-young screw cap. ${ }^{1} \mathrm{H},{ }^{11} \mathrm{~B},{ }^{13} \mathrm{C}\left\{{ }^{1} \mathrm{H}\right\}$, and ${ }^{19} \mathrm{~F}\left\{{ }^{1} \mathrm{H}\right\} \mathrm{NMR}$ spectrum spectra were acquired at $25{ }^{\circ} \mathrm{C}$ on either a Bruker $700 \mathrm{MHz}$, Bruker DRX $600 \mathrm{MHz}$, Bruker ARX $400 \mathrm{MHz}$, or Bruker ARX $300 \mathrm{MHz}$ Spectrometers. Chemical shifts are reported relative to $\mathrm{SiMe}_{4}$ and referenced to the residual solvent signal $\left({ }^{1} \mathrm{H},{ }^{13} \mathrm{C}\left\{{ }^{1} \mathrm{H}\right\}\right)$ of $\mathrm{CDCl}_{3}(\delta 7.26,77.16 \mathrm{ppm})$ or $\mathrm{C}_{6} \mathrm{D}_{6}(\delta 7.16,128.06 \mathrm{ppm}) .{ }^{11} \mathrm{~B}$ and ${ }^{19} \mathrm{~F}\left\{{ }^{1} \mathrm{H}\right\}$ NMR spectrum spectra were referenced relative to $15 \% \mathrm{BF}_{3}-\mathrm{Et}_{2} \mathrm{O}$. NMR spectrum spectra were analyzed using either TopSpin 4.0.1 or MestReNova 12.0.3-21384 software. Chemical shifts are reported in ppm and coupling constants as scalar values in $\mathrm{Hz}$. The conventional abbreviations were used as follows: $s$ (singlet), $d$ (doublet), $d t$ (doublet of triplets), $t$ (triplet), q (quartet), dd (doublet of doublets), $\mathrm{m}$ (multiplet), br (broad). Absorption measurements were recorded with a Cary 5000 UV-Vis-NIR Spectrophotometer from Agilent Technologies. Recordings were obtained at $25^{\circ} \mathrm{C}$ and taken with the instrument operating in single beam mode and referenced to the respective solvent. 
NMR Spectra of Synthesized Compounds

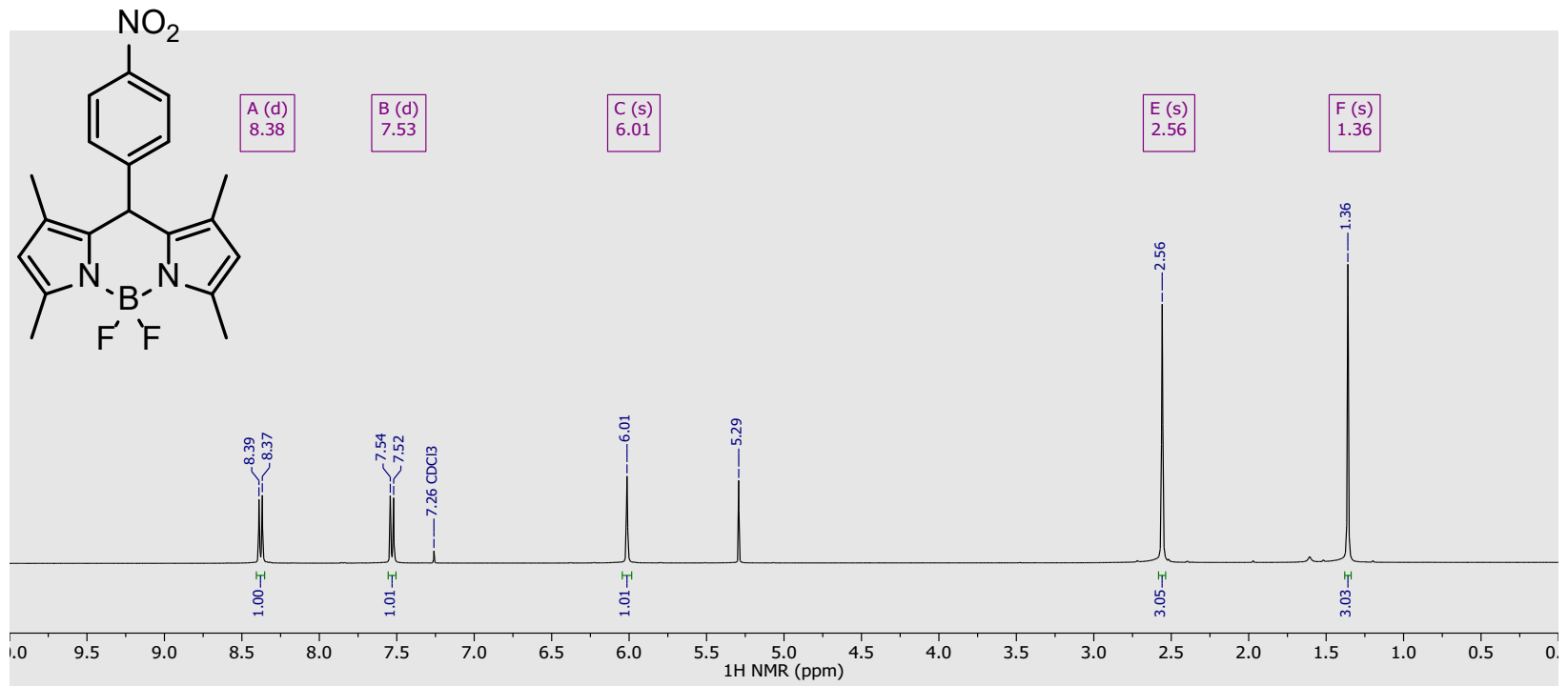

Figure S1. ${ }^{1} \mathrm{H}$ NMR spectrum of $m$-(4-nitrophenyl)-tetramethyl-BODIPY in $\mathrm{CDCl}_{3}$.

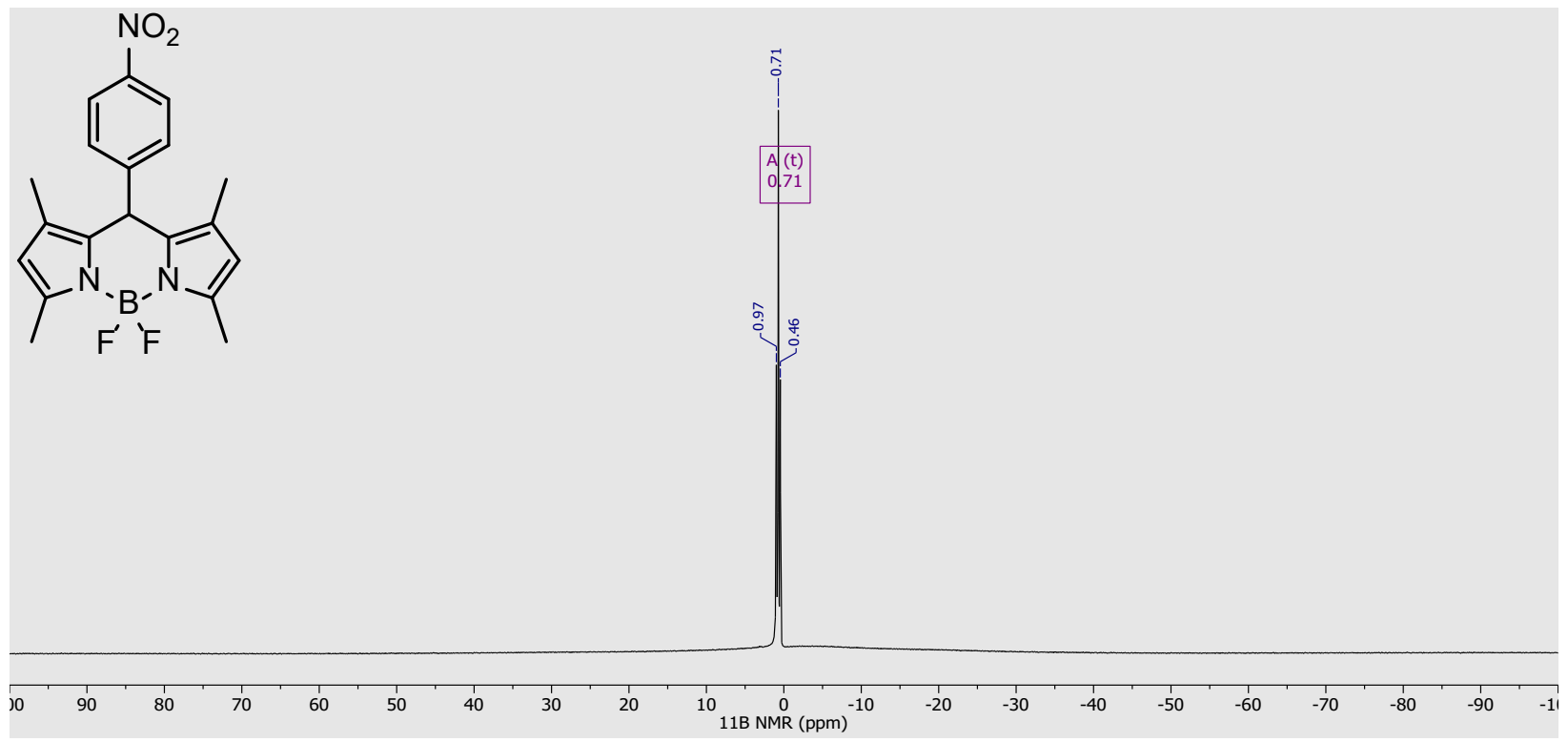

Figure S2. ${ }^{11} \mathrm{~B}$ NMR spectrum of $m$-(4-nitrophenyl)-tetramethyl-BODIPY in $\mathrm{CDCl}_{3}$. 


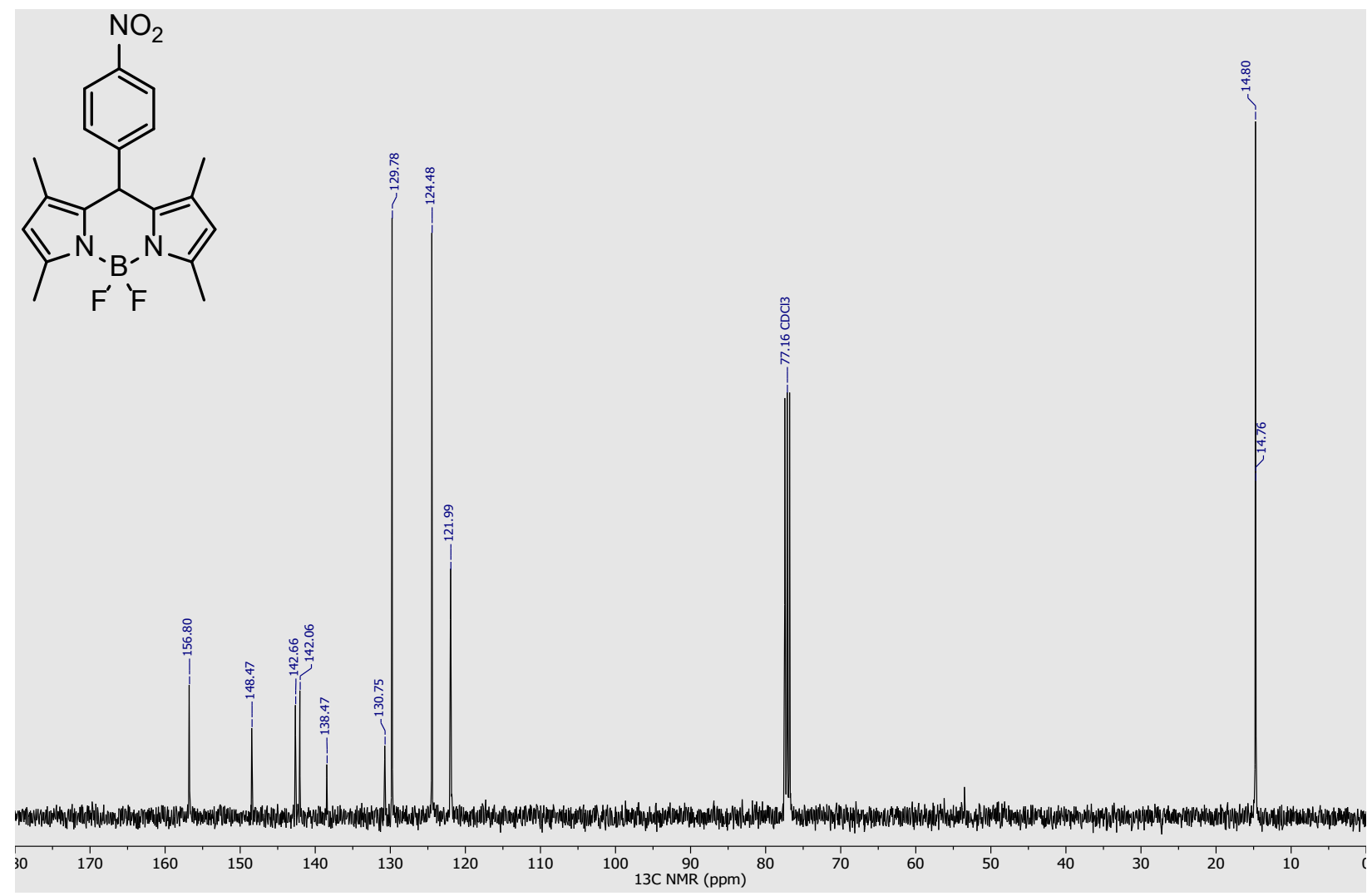

Figure S3. ${ }^{13} \mathrm{C}$ NMR spectrum of $m$-(4-nitrophenyl)-tetramethyl-BODIPY in $\mathrm{CDCl}_{3}$.<smiles>Cc1cc(C)n2c1C(c1ccc([N+](=O)[O-])cc1)c1c(C)cc(C)n1B2F</smiles>

00

Figure S4. ${ }^{19} \mathrm{~F}$ NMR spectrum of $m$-(4-nitrophenyl)-tetramethyl-BODIPY in $\mathrm{CDCl}_{3}$. 


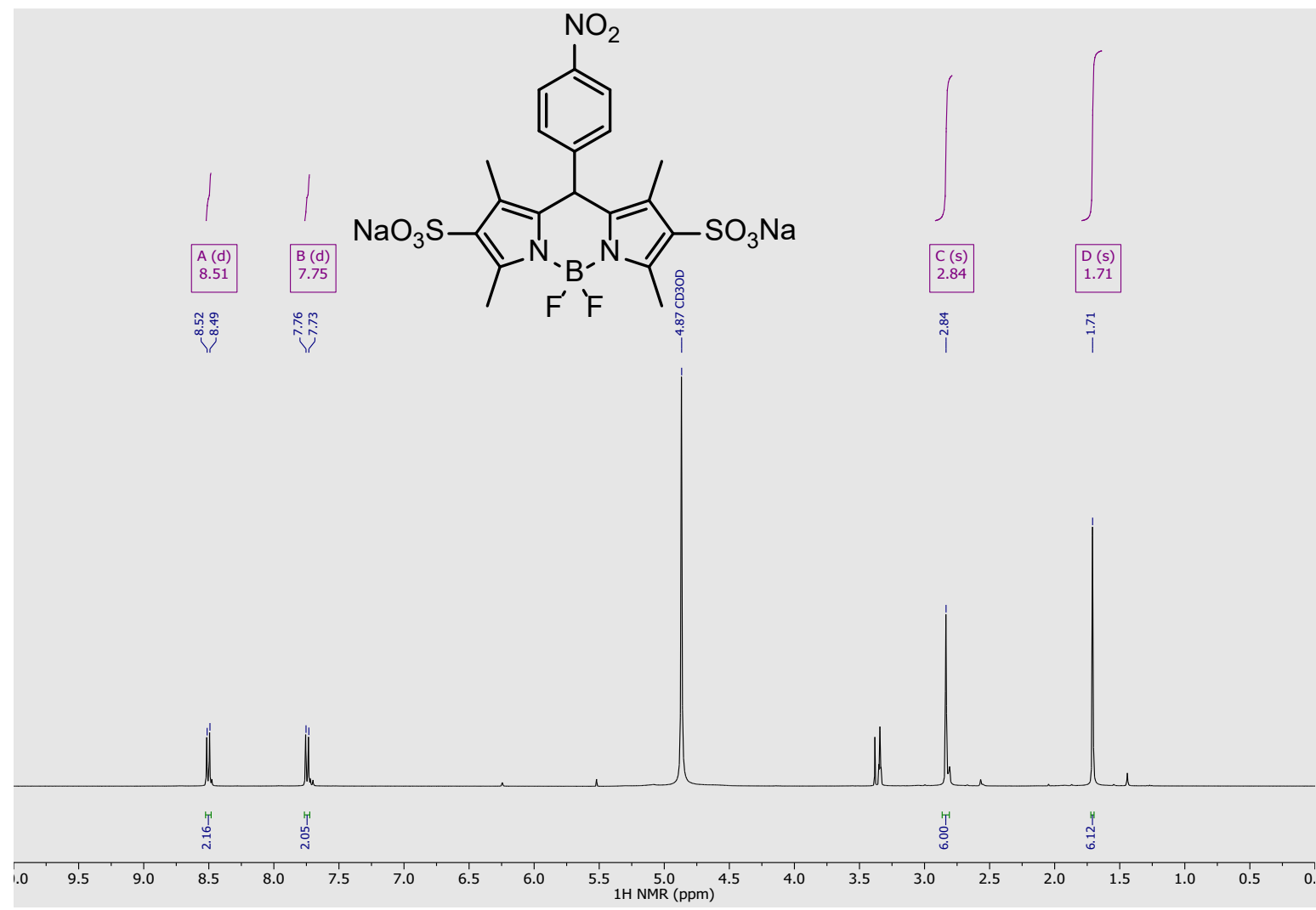

Figure S5. ${ }^{1} \mathrm{H}$ NMR spectrum of sodium 2,6-disulfonyl-m-(4-nitrophenyl)-tetramethyl-BODIPY in $\mathrm{CD}_{3} \mathrm{OD}$.
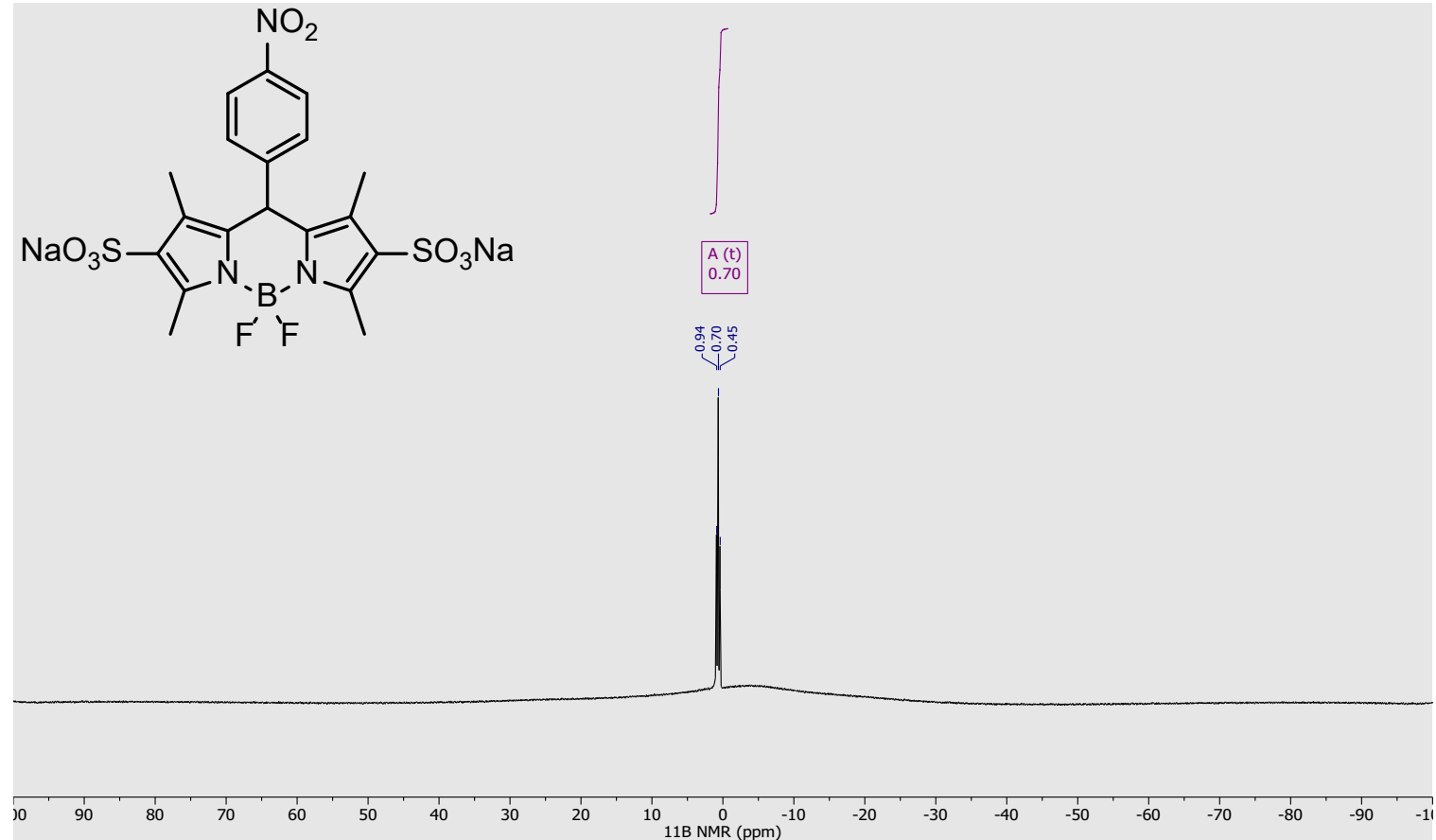

Figure S6. ${ }^{11} \mathrm{~B}$ NMR spectrum of sodium 2,6-disulfonyl-m-(4-nitrophenyl)-tetramethyl-BODIPY in $\mathrm{CD}_{3} \mathrm{OD}$. 


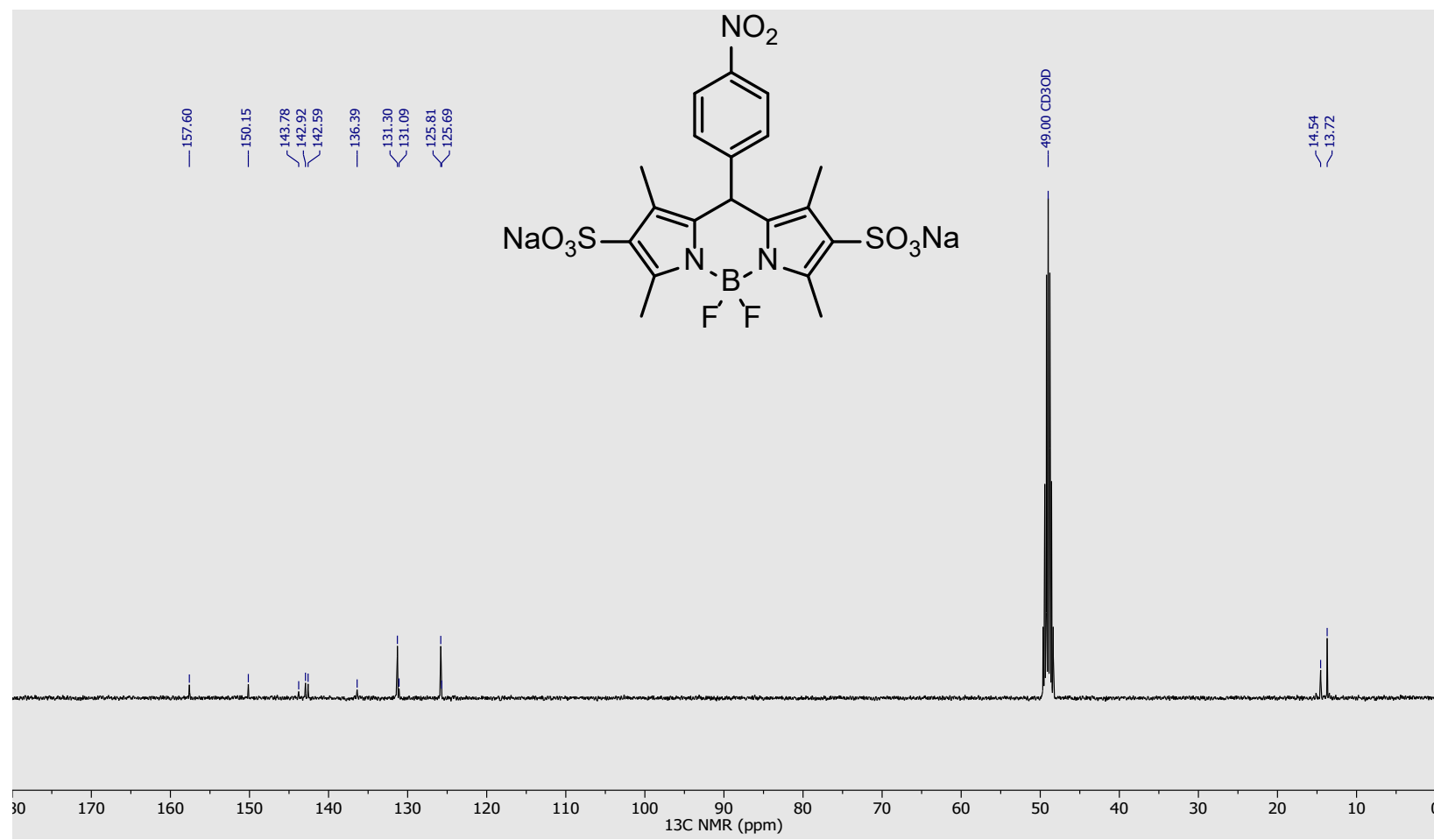

Figure S7. ${ }^{13} \mathrm{C}$ NMR spectrum of sodium 2,6-disulfonyl-m-(4-nitrophenyl)-tetramethyl-BODIPY in $\mathrm{CD}_{3} \mathrm{OD}$.<smiles>Cc1c(S(=O)(=O)O)c(C)n2c1C(c1ccc([N+](=O)[O-])cc1)c1c(C)c(S(=O)(=O)O[Na])c(C)n1B2F</smiles>
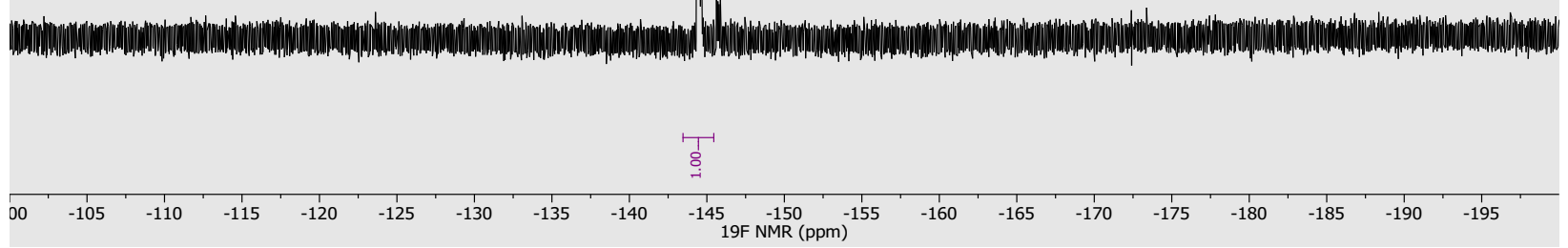

Figure S8. ${ }^{19} \mathrm{~F}$ NMR spectrum of sodium 2,6-disulfonyl-m-(4-nitrophenyl)-tetramethyl-BODIPY in $\mathrm{CD}_{3} \mathrm{OD}$. 

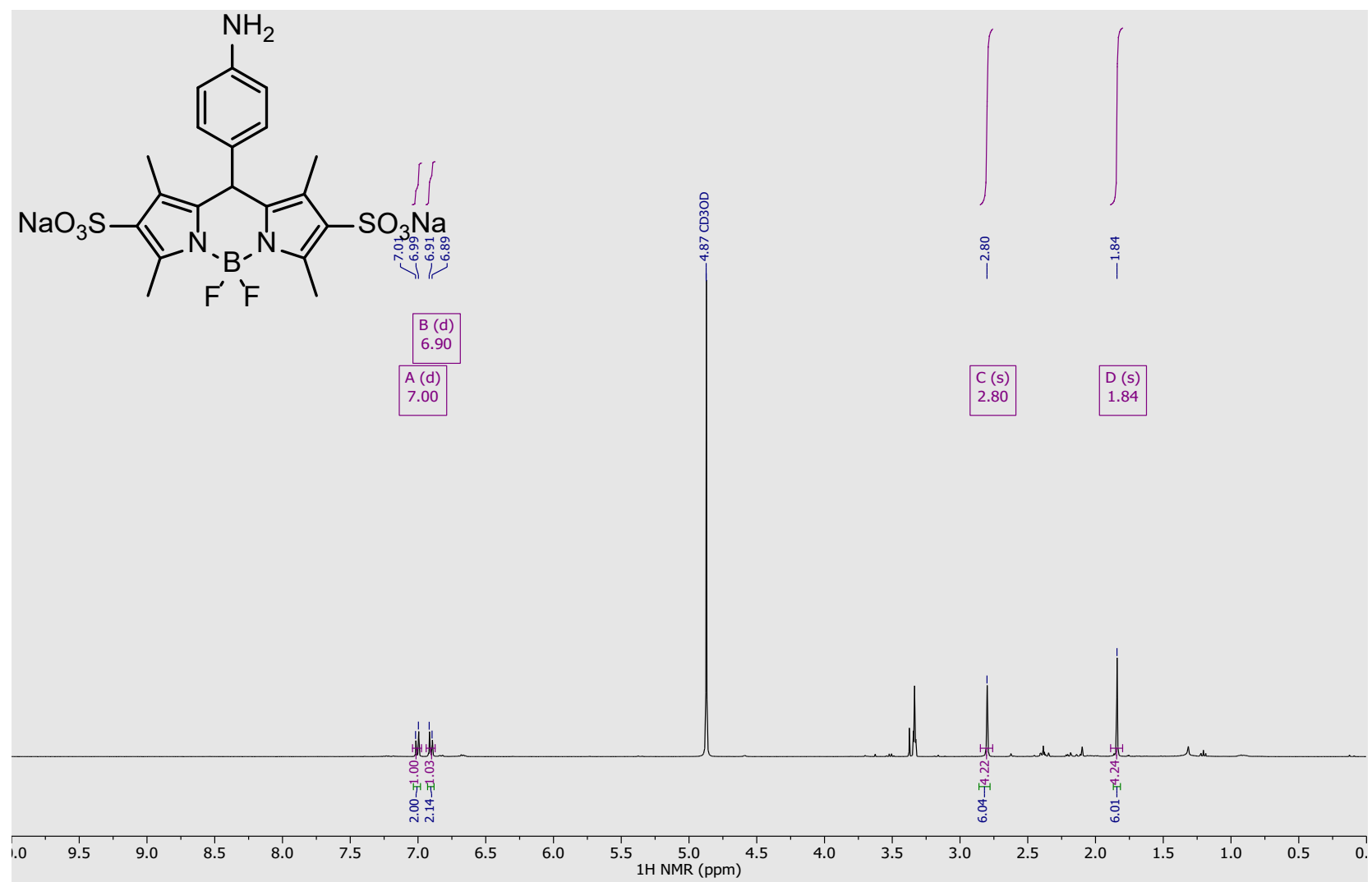

Figure S9. ${ }^{1} \mathrm{H}$ NMR spectrum of sodium 2,6-disulfonyl-m-(4-aminophenyl)-tetramethyl-BODIPY in $\mathrm{CD}_{3} \mathrm{OD}$.
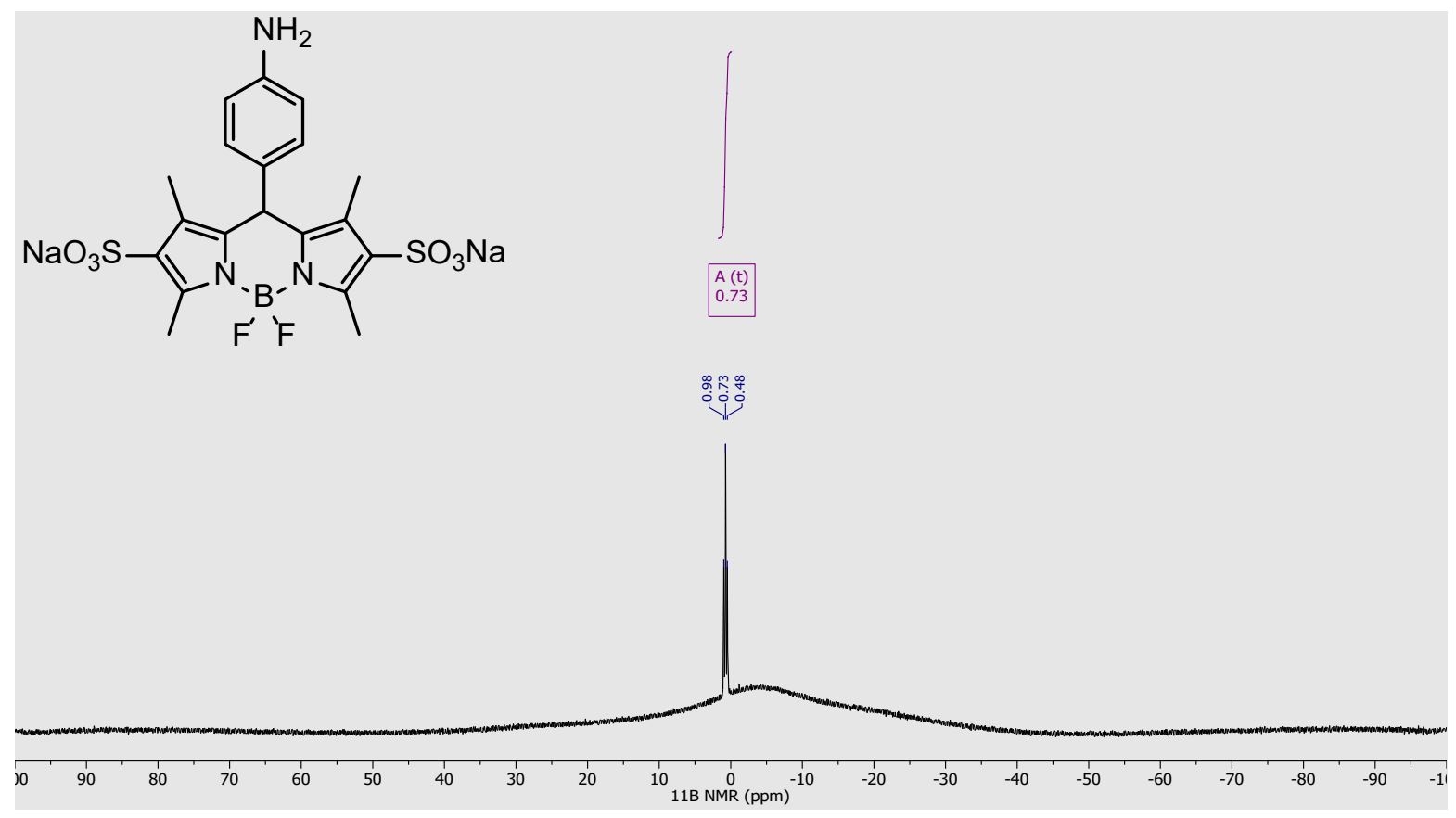

Figure S10. ${ }^{11} \mathrm{~B}$ NMR spectrum of sodium 2,6-disulfonyl-m-(4-aminophenyl)-tetramethylBODIPY in $\mathrm{CD}_{3} \mathrm{OD}$. 


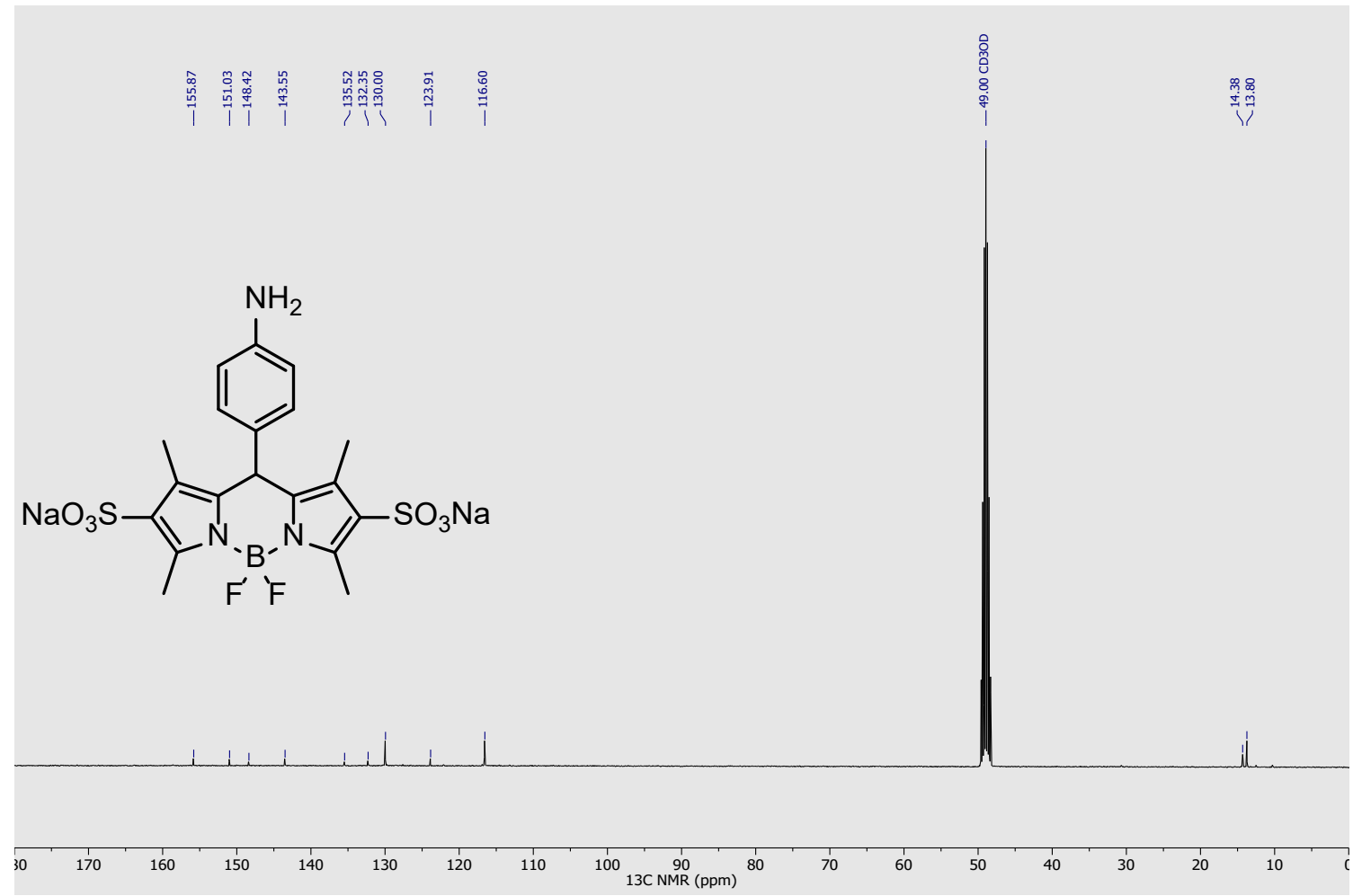

Figure S11. ${ }^{13} \mathrm{C}$ NMR spectrum of sodium 2,6-disulfonyl-m-(4-aminophenyl)-tetramethylBODIPY in $\mathrm{CD}_{3} \mathrm{OD}$.

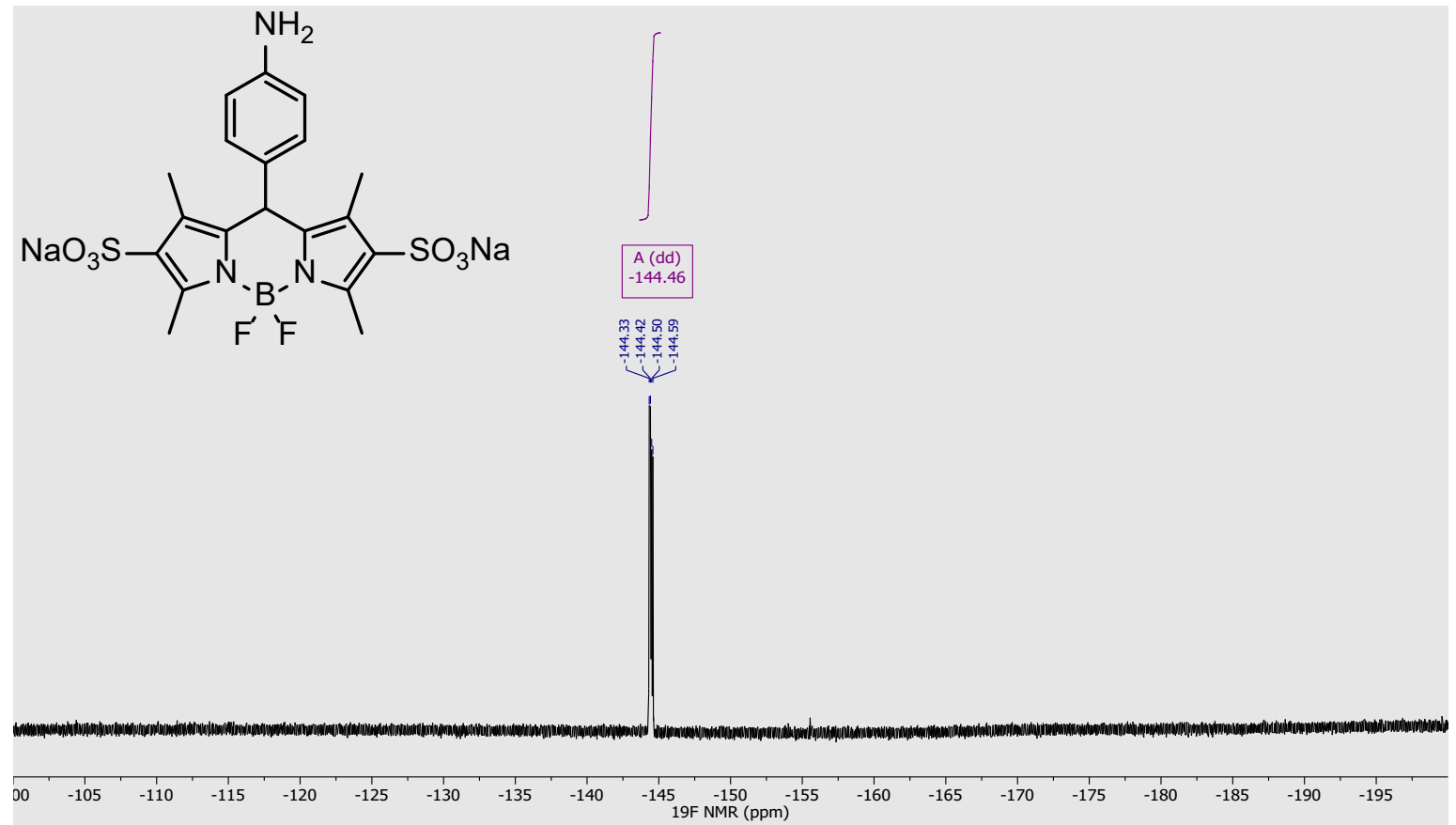

Figure S12. ${ }^{19} \mathrm{~F}$ NMR spectrum of sodium 2,6-disulfonyl-m-(4-aminophenyl)-tetramethyl-BODIPY in $\mathrm{CD}_{3} \mathrm{OD}$. 


\section{Section S2: Mass Balance calculations for the gaseous HONO sampling}

Note all measurements reported in this work have been background corrected by the measurement of ultra pure zero air. All possible fates have been considered to evaluate the experimental system by mass balance. Since the fate of gaseous HONO from the calibration source in the gas handling lines is different from its fate in the aqueous sampling solution, we measure and include the transformations from each part of the experimental system separately. Nitrogen monoxide (NO) is measured by the $\mathrm{NO}$ channel of the $\mathrm{NO}_{x}$ analyzer, while $\mathrm{HONO}$ and $\mathrm{NO}_{2}$ are measured as a sum on the $\mathrm{NO}_{2}$ channel of the $\mathrm{NO}_{\mathrm{x}}$ analyzer. So with potential losses or transformations in the three components of our experiment: calibration source, aqueous phase and, output; we break the $\mathrm{NO}_{\mathrm{x}}$ analyzer measurements into corresponding terms. Since it is not possible to directly measure HONO uptake into the bubbler solution, we needed to define the HONO that is exiting the bubbler and subtract that from the HONO supplied to calculate the loss. Fig S13, which follows the mass balance, shows the schematic of the sampling setup components and gas handling.

\section{S2.1: HONO calibration source responsible for HONO input to bubbler system}

\section{S2.1.1: $\mathrm{NO}_{2}$ channel of the $\mathrm{NO}_{x}$ analyzer}

The $\mathrm{NO}_{2}$ channel quantitatively detects $\mathrm{HONO}$, so the reading of the HONO calibration source is equal to its output. Therefore, this measurement enables quantitation of the HONO input to the bubbler.

Based on this the HONO input (HONO in) could be calculated as in equation 1 (ES1).

$\mathrm{HONO}$ in $=\mathrm{HONO}_{\mathrm{cs}}$

ES1

Thus, the value of $\mathrm{HONO}_{\mathrm{cs}}$ is measured using the $\mathrm{NO}_{2}$ channel of the instrument.

\section{S2.1.2: NO channel of the $\mathrm{NO}_{x}$ analyzer}

Based on previous studies HONO calibration sources can have up to $10 \%$ NO impurities. ${ }^{1}$ This is what is observed in the output of the HONO calibration source used in this work, with NO mixing ratios $\left(\mathrm{NO}_{\mathrm{cs}}\right)$ quantified at $4.1 \mathrm{ppb}$ when generating $\mathrm{HONO}$ at approximately $60 \mathrm{ppb}$. The $\mathrm{NO}_{\mathrm{cs}}$ is measured on the NO channel of the instrument and the impurity coming from the calibration source ( $\mathrm{NO}_{\text {impurity }}$ ) is equal to this (ES2).

$\mathrm{NO}_{\mathrm{cs}}=\mathrm{NO}_{\text {impurity }}$ 


\section{S2.2: Fate of HONO in bulk aqueous solution (aq)}

When HONO goes through acidic solution there are two possible outcomes. Either it will be taken

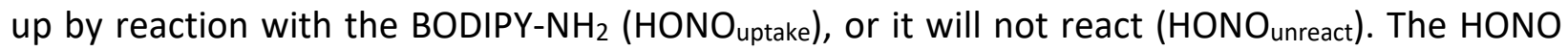
that does not react with BODIPY- $\mathrm{NH}_{2}$ will either end up decomposing through Reaction S1 or

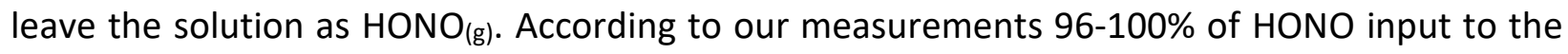
solution was observed to react with the BODIPY- $\mathrm{NH}_{2}$ probe. This suggests that the dominant and preferred fate for $\mathrm{HONO}$ is reaction with the BODIPY- $\mathrm{NH}_{2}$ probe when it is available. However, all the possible outcomes should be considered in the mass balance to understand observations made in the absence of BODIPY- $\mathrm{NH}_{2}$ (ES3).

$2 \mathrm{HONO}_{(\mathrm{aq})} \rightarrow \mathrm{NO}_{(\mathrm{g})}+\mathrm{NO}_{2(\mathrm{~g})}+\mathrm{H}_{2} \mathrm{O}$

RS1

$\mathrm{HONO}$ unreact $=\mathrm{HONO}_{\mathrm{aq}}+\mathrm{HONO}_{\mathrm{aq} \_ \text {Decomp }}$

ES3

Where the $\mathrm{HONO}_{\mathrm{aq}}$ is the moles of $\mathrm{HONO}$ that come out of the solution in the form of $\mathrm{HONO}$ and the $\mathrm{HONO}_{\text {aq_Decomp }}$ is the amount of HONO decomposed in the solution

\section{S2.3: Impinger output measurements}

\section{S2.3.1: NO channel}

The main assumption here is that any NO will not be lost at $\mathrm{pH} 0$. This means that any NO impurity from the calibration source ( $\mathrm{NO}_{\text {impurity }}$ ) would pass through the bubbler unaltered and be

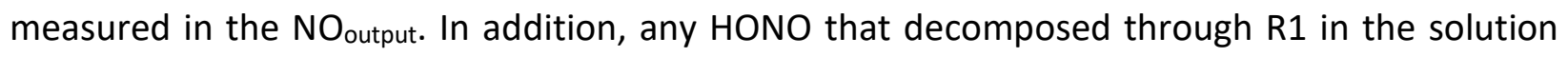
would also be measured in the $\mathrm{NO}_{\text {output. }}$ According to RS1, the amount of $\mathrm{NO}_{2}$ produced from the $\mathrm{HONO}$ decomposition is equal to the amount of $\mathrm{NO}$ produced. The sum of $\mathrm{NO}$ and $\mathrm{NO}_{2}$ produced from decomposition would represent the amount of $\mathrm{HONO}$ that is decomposed ( $\mathrm{HONO}_{\mathrm{aq}}$, Decomp) according to Equation S4.

NO Output $=\left(\mathrm{NO}_{\text {impurity }}\right)+\left(\mathrm{HONO}_{\text {aq_Decomp }} / 2\right)$

ES4

\section{S2.3.3: $\mathrm{NO}_{2}$ channel}

The $\mathrm{NO}_{2}$ channel on the NOx analyser would measure any HONO that came out of the solution and also any $\mathrm{NO}_{2}$ due to the decomposition of $\mathrm{HONO}$ in aqueous phase (Equation S5). Thus, the measured $\mathrm{NO}_{2}$ in the impinger output (defined as $\mathrm{NO}_{2}$ output) would represent the sum of HONO and $\mathrm{NO}_{2}$ as per Eqn $\mathrm{S} 5$.

$\mathrm{NO}_{2 \text { output }}=\mathrm{HONO}_{\mathrm{aq}}+\left(\mathrm{HONO}_{\text {aq_Decomp }} / 2\right)$

Taking the sum of ES4 and ES5 we arrive at Equation S6:

$\mathrm{NO}_{\text {output }}+\mathrm{NO}_{2 \text { output }}=\mathrm{HONO}_{\mathrm{aq}}+\mathrm{HONO}_{\text {aq_Decomp }}+\mathrm{NO}_{\text {impurity }}$ 
Then, drawing from ES3:

$\mathrm{NO}_{\text {Output }}+\mathrm{NO}_{2}$ output $=\mathrm{HONO}_{\text {unreact }}+\mathrm{NO}_{\text {impurity }}$

Next, incorporating a rearrangement for $\mathrm{NO}_{\text {impurity }}$ from ES2 into this, the unreacted $\mathrm{HONO}$ is quantified according to Equation S7.

$\mathrm{HONO}_{\text {unreact }}=\left(\mathrm{NO}_{\text {Output }}+\mathrm{NO}_{2}\right.$ output $)-\left(\mathrm{NO}_{\text {cs }}\right)$

ES7

This then allows the calculation of the desired $\mathrm{HONO}_{\text {uptake }}$ quantity according to Equation S8.

$\mathrm{HONO}_{\text {uptake }}=\mathrm{HONO}_{\text {in }}-\mathrm{HONO}_{\text {unreact }}$

ES8

By replacing $\mathrm{HONO}_{\text {in }}$ from ES1 and $\mathrm{HONO}_{\text {unreact }}$ from ES3 $\mathrm{HONO}_{\text {uptake }}$ can be calculated from the measurements made by the NOx analyzer using Equation S9.

$\mathrm{HONO}_{\text {uptake }}=\mathrm{HONO}_{\mathrm{cs}}-\left[\mathrm{NO}_{\text {Output }}+\mathrm{NO}_{2}\right.$ Output $\left.-\left(\mathrm{NO}_{\mathrm{cs}}\right)\right]$

ES9

To test if there was disproportionation of $\mathrm{HONO}$ in the absence of reaction with BODIPY- $\mathrm{NH}_{3}{ }^{+}$or aniline via RS1, gaseous HONO $(17 \pm 0.2 \mathrm{ppbv})$ was bubbled through $1 \mathrm{M} \mathrm{HCl}$, and the impinger output was measured with a $\mathrm{NO}_{x}$ analyzer (Fig S13). From Fig S13, the NOx level at the output of the impinger increased over time and reached a steady state $(700 \mathrm{~min})$, replicating the observations of the corresponding control experiment (Fig 7). While the $\mathrm{NO}_{\mathrm{x}}$ level exiting the impinger output reached this steady state, it was then scrubbed using an annular denuder (URG, $\mathrm{NC}$, USA) coated with $\mathrm{Na}_{2} \mathrm{CO}_{3}$ to remove any $\mathrm{HONO}$ (Fig S13, $1000 \mathrm{~min}$ ). Thus, the difference in the $\mathrm{NO}_{2}$ channel measurement before and after the insertion of the denuder into the gas flow would be equal to the HONO mixing ratio. The observed decrease in measured $\mathrm{NO}_{2}$ (Fig S13, 12.5 ppbv), demonstrates that most of the HONO going into the impinger also exited it as molecular HONO (76\%), and the remaining difference is explained by known chemistry where the HONO is decomposing in solution (e.g., RS1).

We observed a slightly higher $\mathrm{NO}$ mixing ratio than $\mathrm{NO}_{2}$ mixing ratio when the impinger output was passing through the denuder (Fig S13). This observation suggests that the RS1 is not the sole mechanism controlling HONO decomposition, but the difference is less than $5 \%$ of total HONO going into the solution, suggesting an NO-producing mechanism of minor importance. We do not expect this minor pathway to add significant error in our analysis for to three reasons. The HONO calibration source mixing ratio has a precision ranging from $10-25 \%$, with $<10 \%$ NO impurity ${ }^{1}$. Thus we expect that the variability in HONO mixing ratio delivered to the experimental impinger would have the most contribution to the uncertainty in the mass balance via NO. Second, we expect this increase in NO production to only happen without the presence of BODIPY- $\mathrm{NH}_{3}{ }^{+}$or aniline since initially $\mathrm{NO}$ and $\mathrm{NO}_{2}$ mixing ratios are equal (e.g. see Fig $\mathrm{S} 13,100 \mathrm{~min}$ ). Since the mass balance calculation is performed when the impinger $\mathrm{NO}_{x}$ output increases, this should not have any influence. Third, the NO output of impinger ( $\mathrm{NO}_{\text {Output) }}$ is taken into account in the mass 
balance (see ES9), as long as the unknown HONO to NO conversion [i.e. not RS1] follows a 1:1 mole ratio, and will again have no effect.

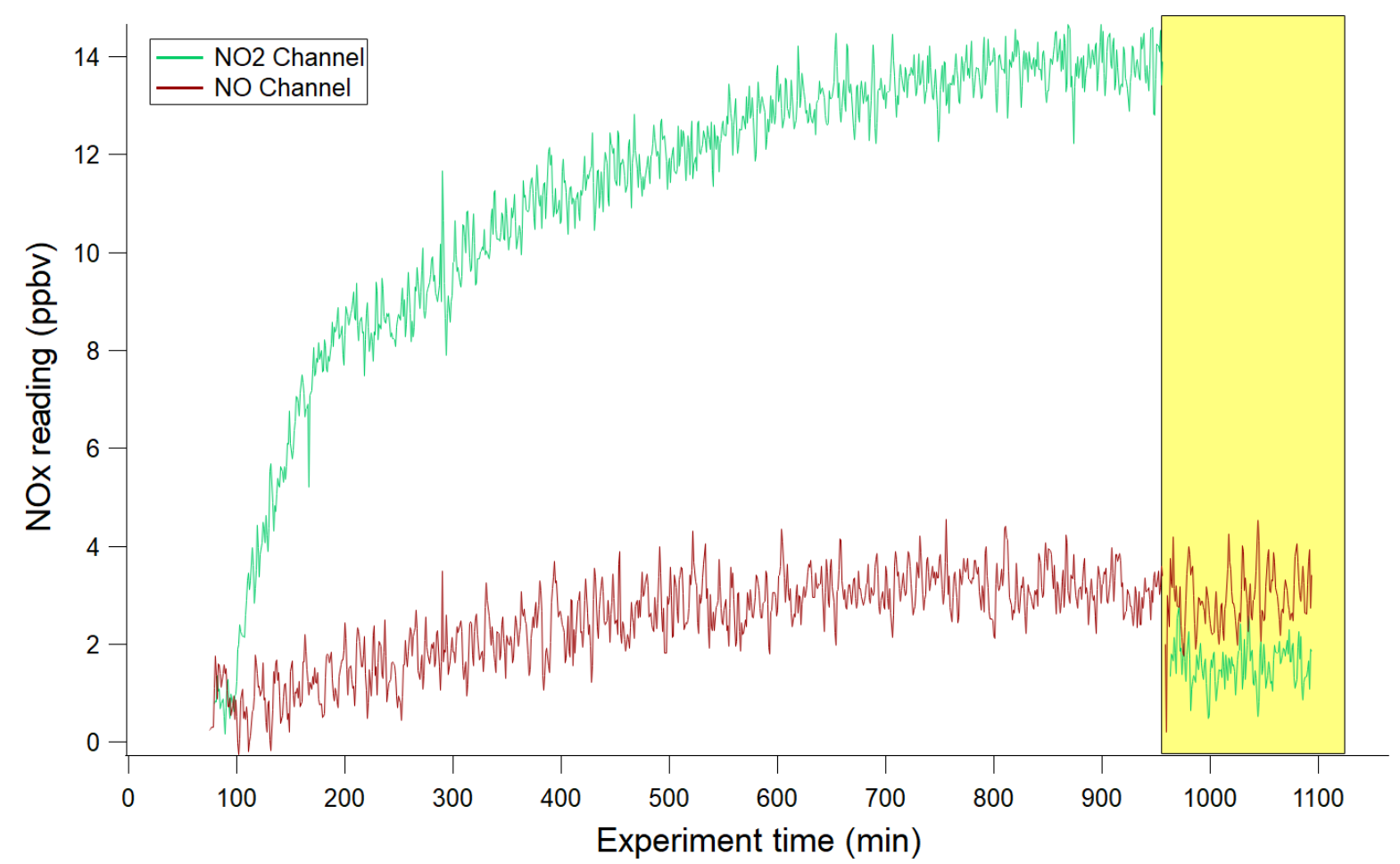

Fig S13. Measurement of the impinger output containing $1 \mathrm{M} \mathrm{HCl}$ when bubbled with $17 \pm 0.2 \mathrm{ppbv}$ of HONO. The yellow box indicates when the impinger output going through denuder coated with $\mathrm{Na}_{2} \mathrm{CO}_{3}$. 


\section{Section S3: Supporting Figures}

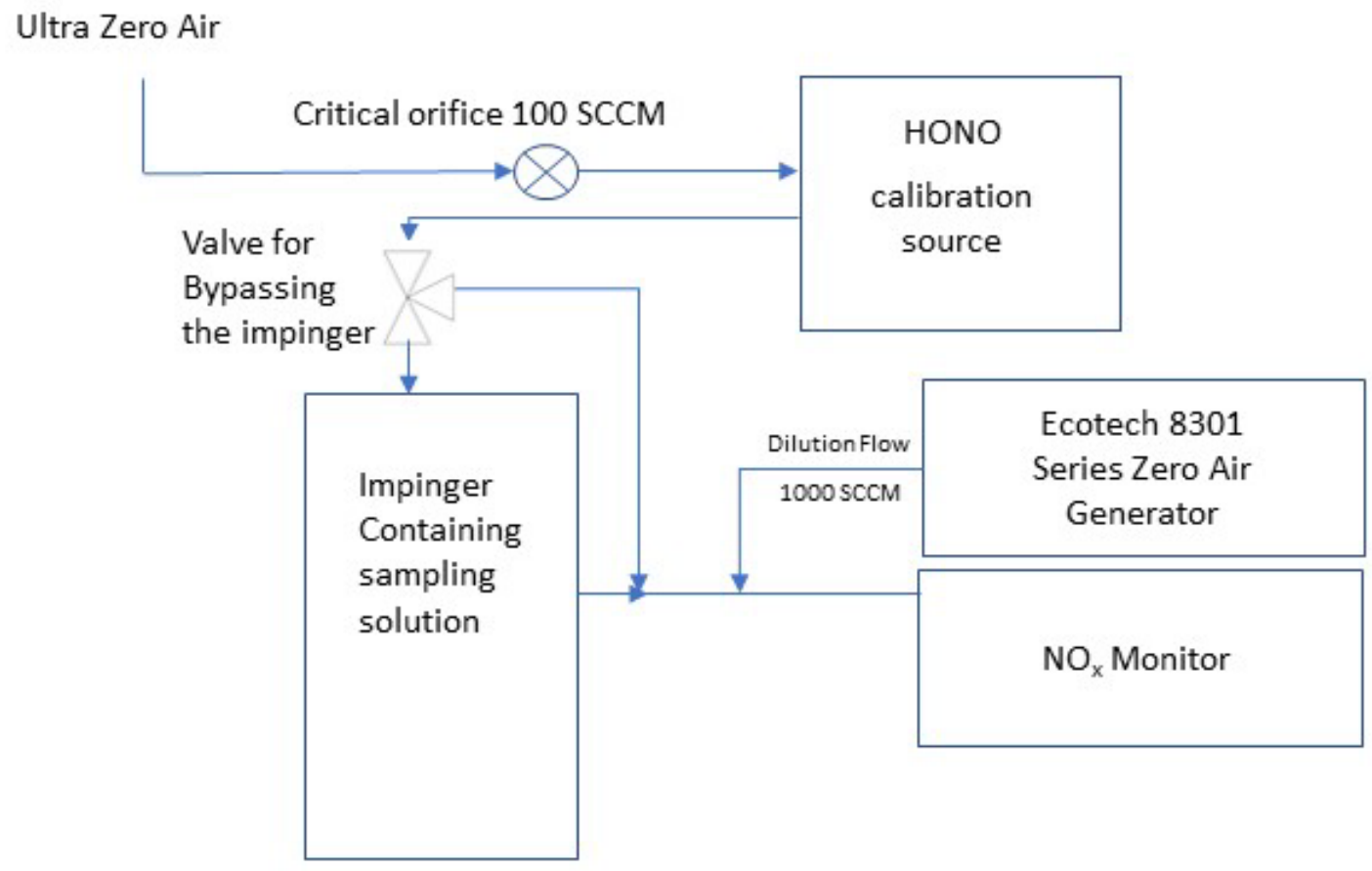

Fig S14. The gas flow and instrumental components of the HONO sampling experiments. 


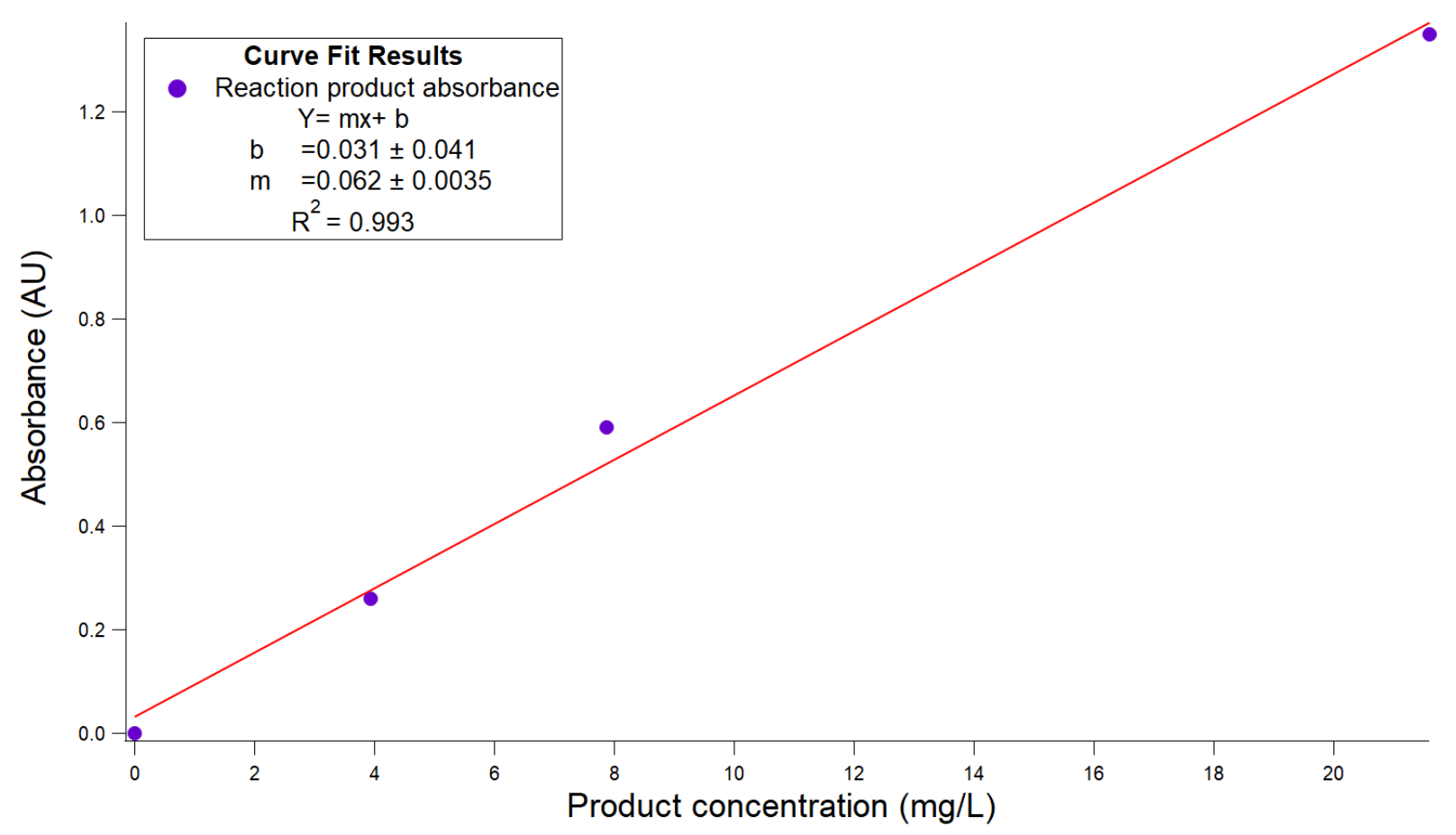

Fig S15. Calibration curve for the absorbance of reaction products of BODIPY- $\mathrm{NH}_{3}{ }^{+}$with 10 times excess nitrite on a molar basis ( $n=4$, including blank) 


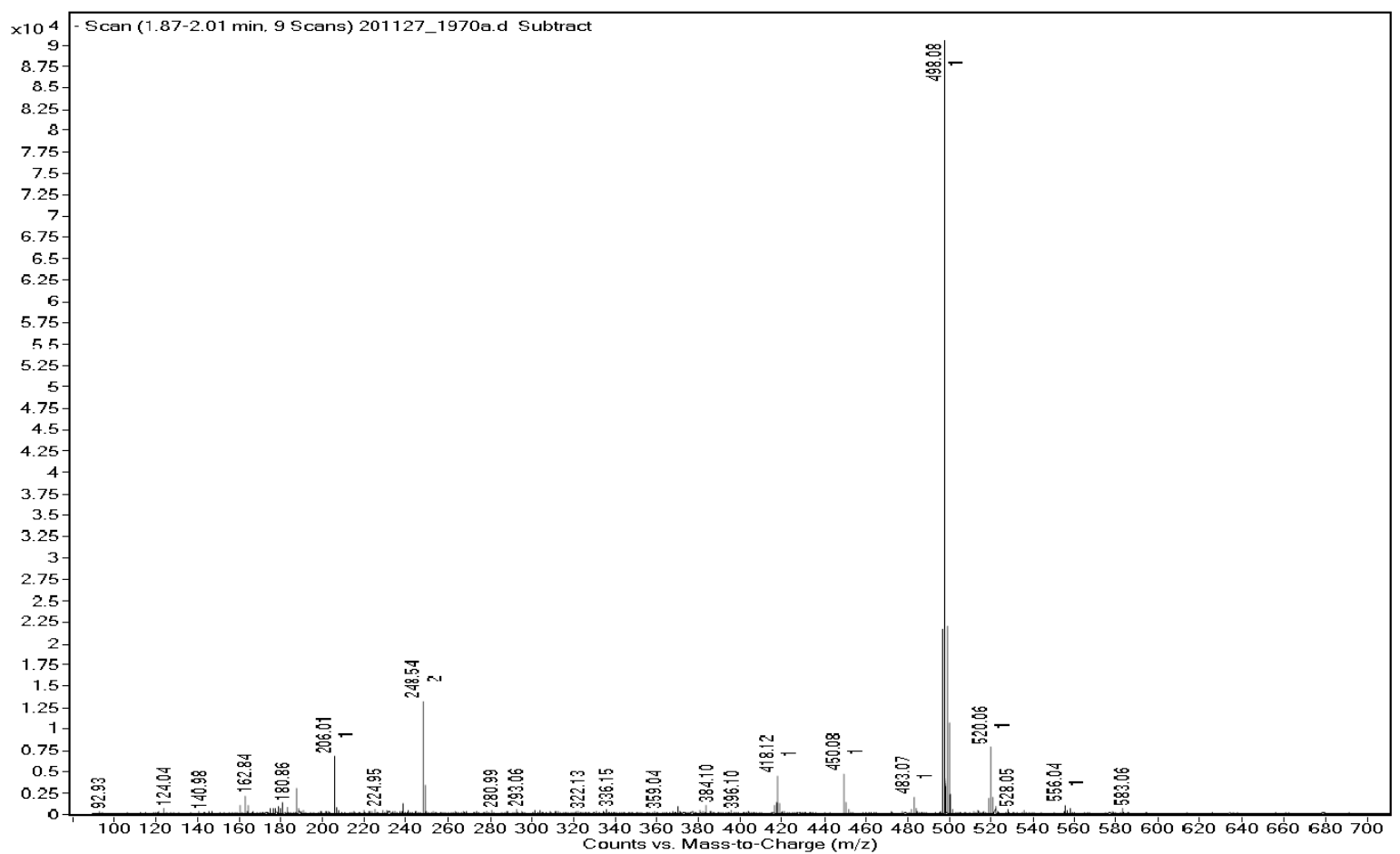

Fig S16. Mass spectra of $314 \mu \mathrm{g} / \mathrm{mL}$ BODIPY- $\mathrm{NH}_{2}$ acidified with eight drops of concentrated $\mathrm{HCl}$ as an unreacted sample 


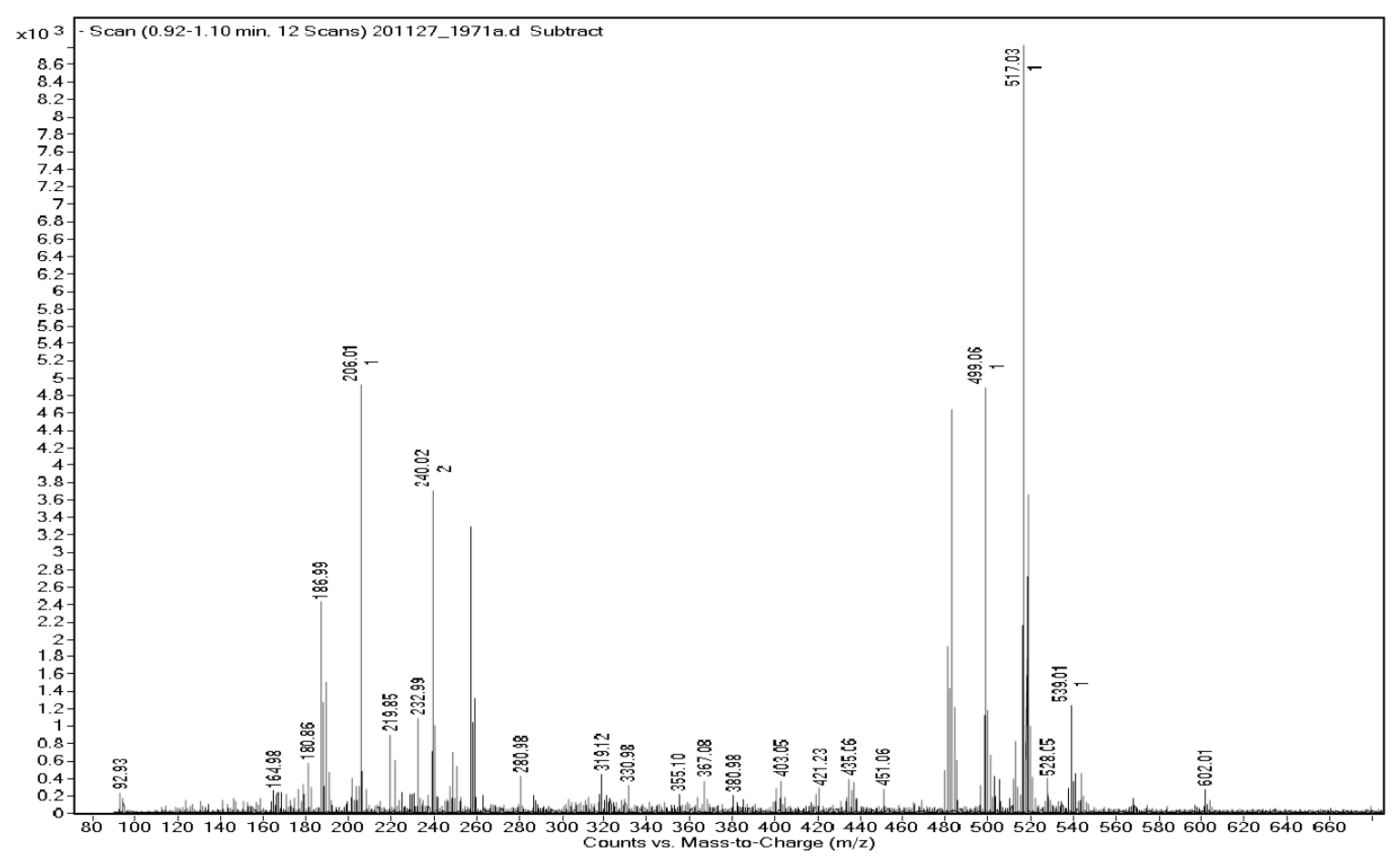

Fig S17. Mass spectra of $2.5 \mathrm{~mL} 314 \mu \mathrm{g} / \mathrm{mL}$ BODIPY- $\mathrm{NH}_{2}$ acidified with eight drops of concentrated $\mathrm{HCl}$ and reacted with $0.5 \mathrm{~mL}$ of $2360 \mu \mathrm{g} / \mathrm{mL} \mathrm{NaNO} \mathrm{NaN}_{2}$ 


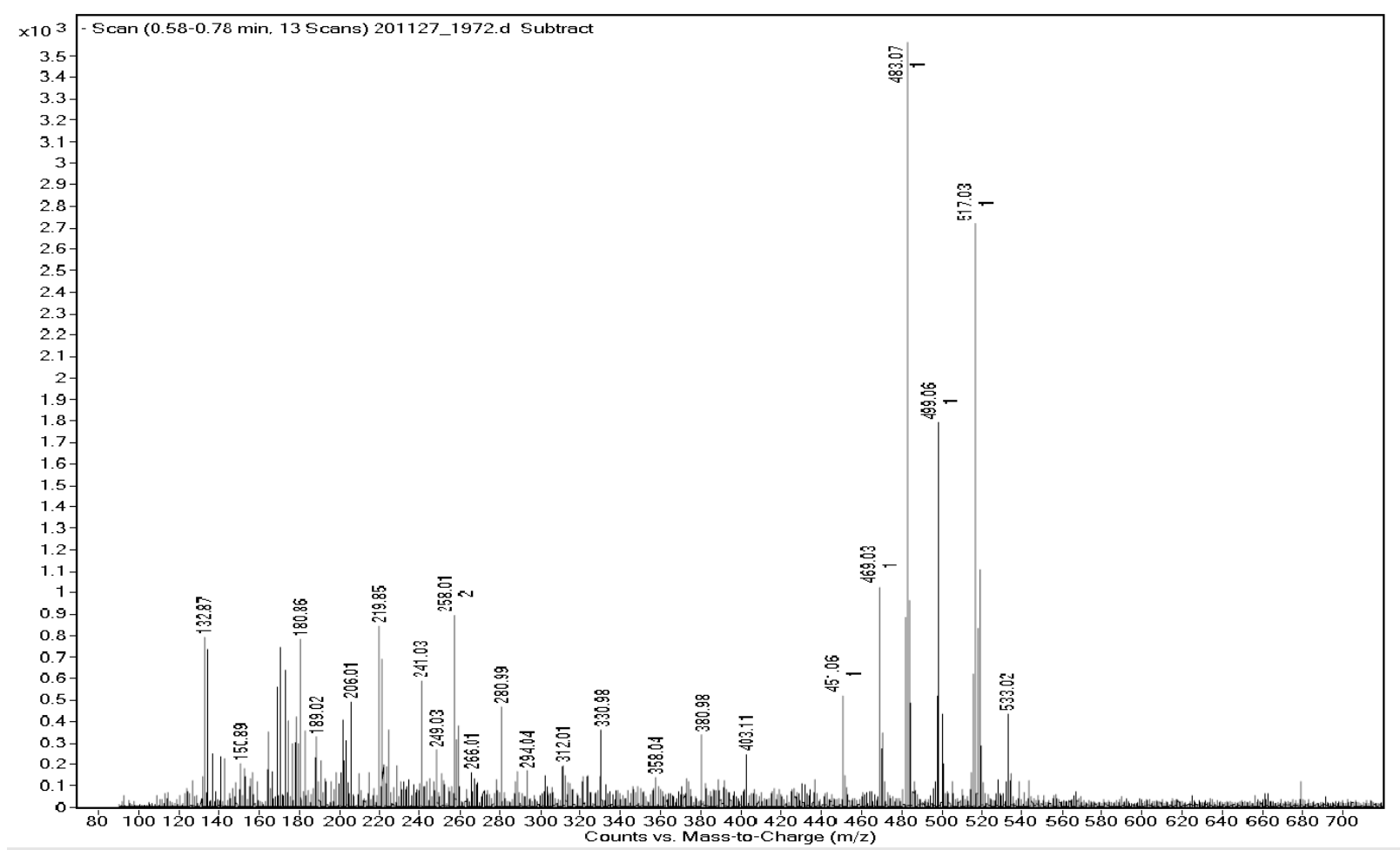

Fig S18. Mass spectra of absorbance of BODIPY- $\mathrm{NH}_{2}$ in $1 \mathrm{M} \mathrm{HCl}$ after bubbled with $25 \pm 14$ ppbv of HONO for three days 


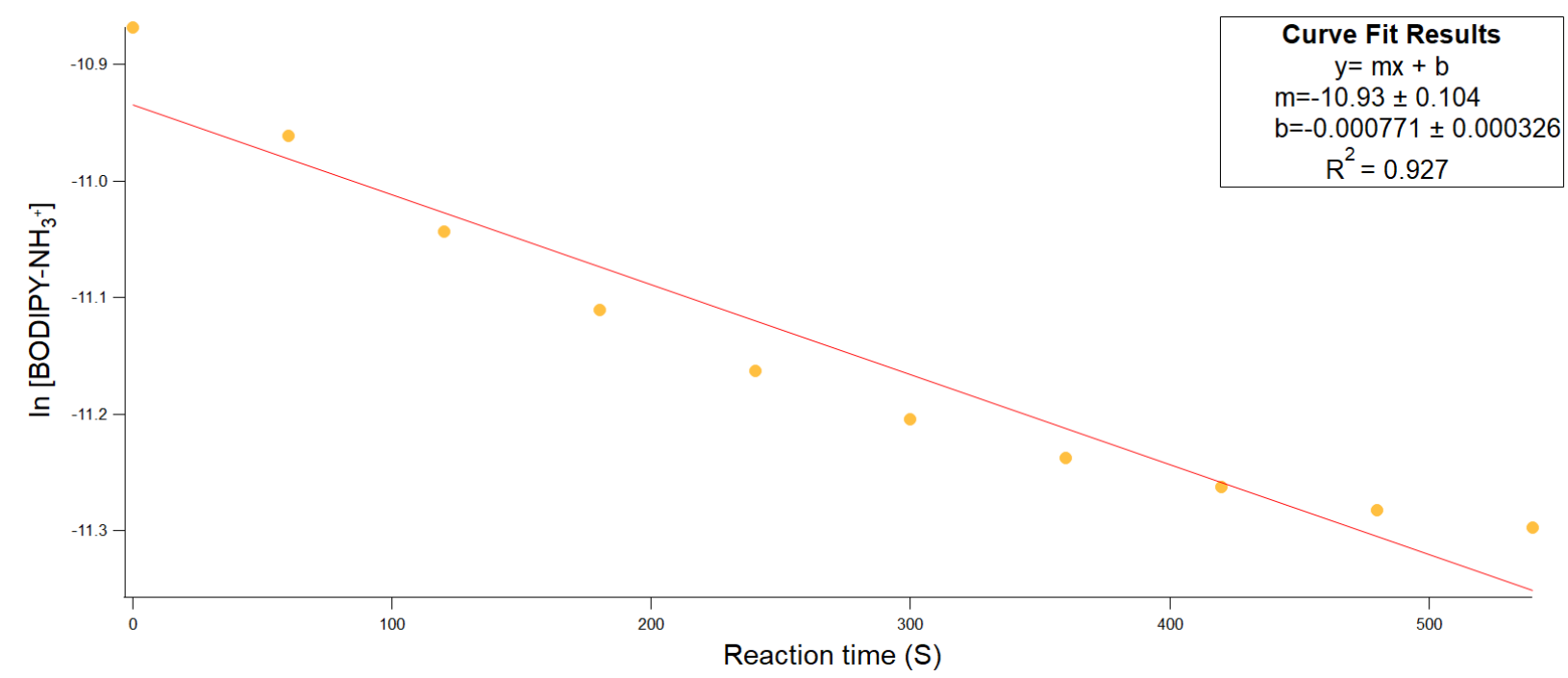

Fig S19. Changes in natural logarithm of BODIPY- $\mathrm{NH}_{3}{ }^{+}$concentration vs time. The absolute value of the slope shows the pseudo-first order reaction rates 


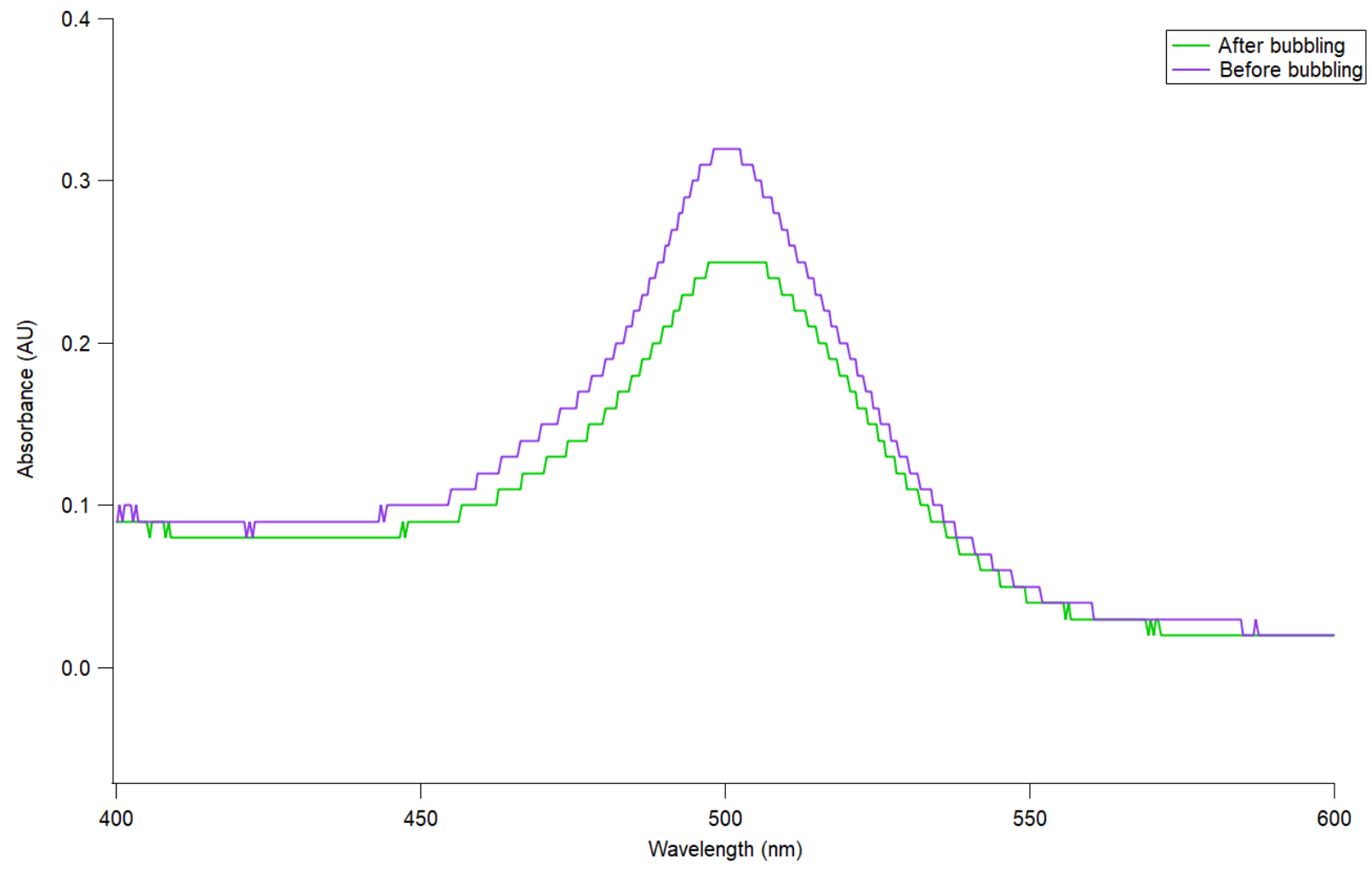

Fig S20. The loss of the reaction product exclusively by the bubbling with $\mathrm{N}_{2}$ using the fritted impinger. 


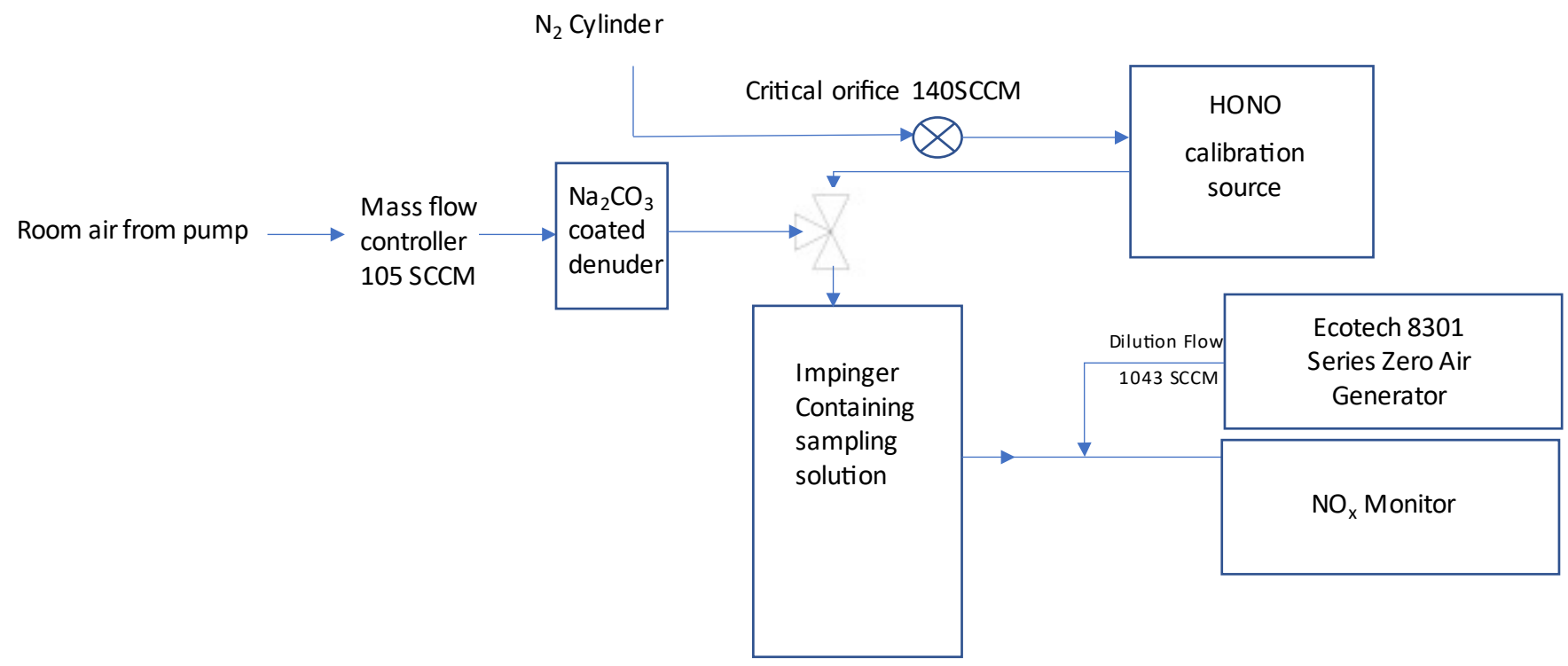

Fig S21. Schematic of the experimental set up for the HONO sampling experiment in the indoor air. 


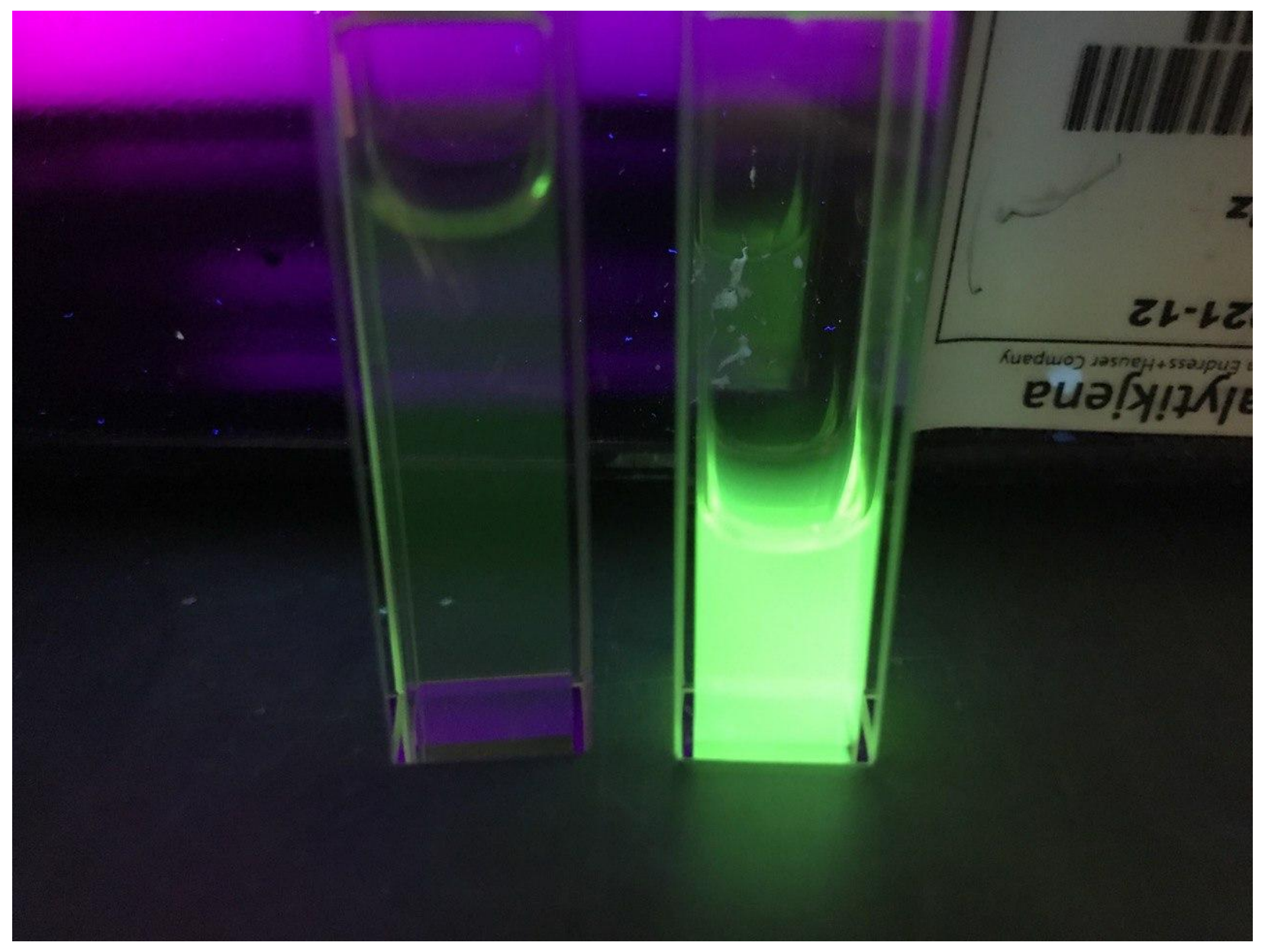

Fig S21. Emission of BODIPY- $\mathrm{NH}_{3}{ }^{+}$(on the right) compared with the product (on the left) 


\section{References}

1 M. Lao, L. R. Crilley, L. Salehpoor, T. C. Furlani, I. Bourgeois, J. Andrew Neuman, A. W. Rollins, P. R. Veres, R. A. Washenfelder, C. C. Womack, C. J. Young and T. C. Vandenboer, Atmos. Meas. Tech., 2020, 13, 5873-5890. 